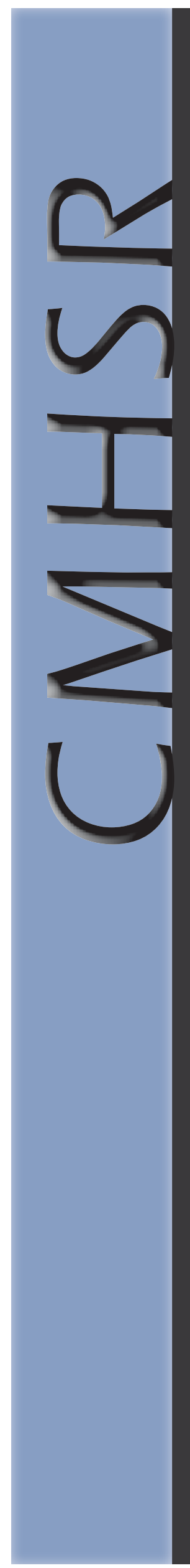

November 2009

Center for Mental Health Services Research

Vol 6, Issue 3

University of Massachusetts Medical School

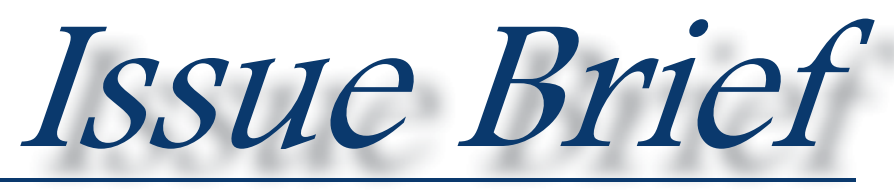

\title{
Confidentiality Uncovered: Why Peer Supporters Need Protection
}

Antonia Seligowski, BA \& Albert J. Grudzinskas, Jr., JD

$\mathrm{T}$ The concept of confidentiality arises from legal recognition given to the expectations of parties in a relationship. The party conveying the information has an expectation of privacy and the party hearing the information has an obligation not to disclose. More importantly, the concept of privilege arises when legal recognition is given to those communications. Privilege prevents compelled disclosure in legal settings. There is currently no recognized privilege protection for communications made to researchers absent a Certificate of Confidentiality. ${ }^{1}$ With the few exceptions that we will discuss, there is also no recognized privilege for communications made to peer supporters.

Peer supporters are becoming increasingly more important in clinical and research settings. For the purposes of this brief, peer supporters are defined as individuals with a history of mental illness or substance abuse who are providing services and/or supports to others diagnosed with a similar illness. ${ }^{2}$ The increasing use of peer supporters is largely due to research findings and transformation efforts that suggest that peers are able to easily build effective relationships with clients and help promote recovery. ${ }^{3,4}$ Peers have been shown to have the ability to act as positive role models with personal experiences to share, and are often more empathetic than non-peers. ${ }^{5}$ Unfortunately peers may not be protected from the consequences of compelled disclosure of information they gain. In Massachusetts, peers can be subpoenaed by a court to repeat any information they obtain from clients/ research subjects. The authors will discuss strategies which could protect peers under these circumstances.

C 2009 Center for Mental Health Senvices Research Department of Psychiatry University of Massachusetts Medical School

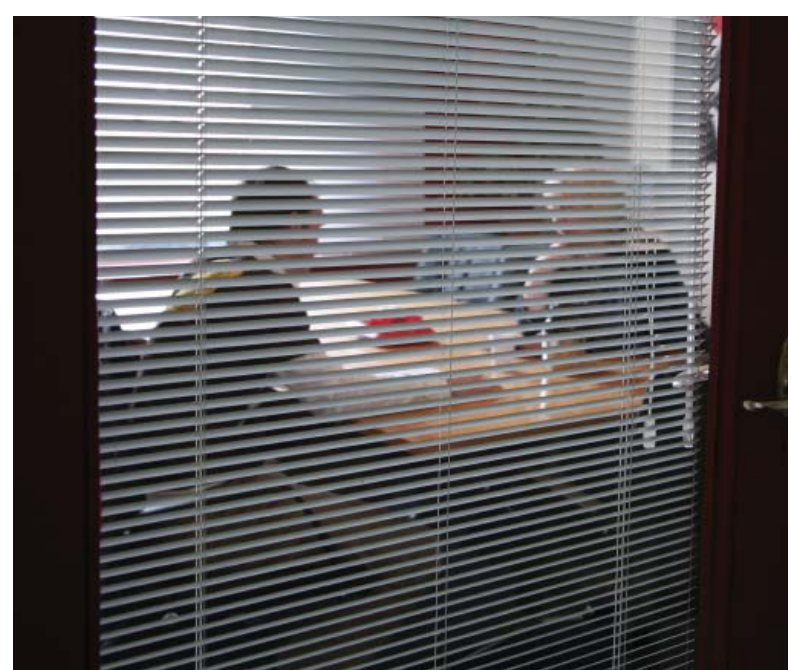

The Myth of Confidentiality

The concept of confidentiality in treatment asserts that information gathered within certain legally defined relationships will be kept private. In research, there is no assurance that confidentiality exists to protect subjects from having their information disclosed. In order to truly ensure confidentiality, researchers must obtain a federal Certificate of Confidentiality. This certificate protects researchers from being subpoenaed to disclose information obtained in the course of a study. However, it may not protect peer supporters in the same way. In fact, when peer supporters are used in conjunction with research as providers of care but are not part of the research team, they may not be protected at all. The court may subpoena any peer supporter to repeat what was disclosed to him or her. This puts the client at risk of self-incrimination and also puts the peer supporter at risk of compromising any trusting relationship they may have established with the subject. There are some settings in which peers do have some protection. As a result of case law in Massachusetts, any communication during the peer counseling of police officers is confidential and peers are not legally bound to repeat information. ${ }^{6}$ Officer peers are protected by privilege and may withhold information as confidential when serving as a witness in court. 


\section{Legal Precedents}

In 1996 an Alcoholics Anonymous group member revealed a prior crime that he committed. ${ }^{7}$ After being charged for this crime, the other members who were present at the meeting were subpoenaed to testify. When the members asked that the comments made during the meeting not be disclosed because they were protected by privilege, the court denied their request. ${ }^{7}$ The defendant, Paul Cox, was charged with murder as a result of the testimony. If individual communications in peer run groups such as AA were protected by privilege, their disclosure could not be compelled.

In another 1996 case the United States Supreme Court recognized the existence of a psychotherapist-patient privilege in Jaffee v. Redmond. ${ }^{8}$ It was noted that privilege between a psychotherapist and their patient not only serves private interests by fostering confidence and trust, but it also serves the public interest by facilitating mental health treatment of all citizens. ${ }^{8}$ This was the first case in which the court recognized a privilege which extends beyond psychiatrists and psychologists to non-doctoral psychotherapists. The role of peer supporters is quite similar to that of licensed professionals and therefore the ruling in this case could be used in support of granting them privilege.

\section{Advantages of Peer Privilege}

If peer supporters were granted privilege by statute, they would have the same protection as psychiatrists, psychologists, licensed social workers and lawyers. Therefore, they would not be legally obligated to repeat information and would be able to forge more trusting relationships with clients and research subjects.

Implications:

- In treatment settings: clients may be more willing to readily discuss issues relevant to treatment, such as illicit drug use.

- In research: investigators may be able to learn more about hard-to-reach populations who previously would not have disclosed information knowing they could be implicated for it.

Knowing that their information is truly protected, subjects could disclose previously concealed risky activities and behaviors, which would promote understanding of these populations and improvement in treatment.

\section{Recommendations}

\section{How to grant privilege to peer supporters:}

- Train peer supporters in the areas of confidentiality and privilege so that they understand these concepts and their importance. Although training has been done in some instances ${ }^{9}$, it ought to be replicated and become a requirement in all settings where peer supporters are utilized.

- Require all peer supporters to be certified. This would standardize the process and prerequisites for being a peer supporter. It would also clarify their role in treatment and research settings, making them significant and accountable members of the communities they work in.

- Brief other professionals on the importance of peer supporters and their need for privilege.

Peer supporters are now being recognized as essential components to recovery and to the understanding of hard-to-reach populations. For this reason, they ought to be given more protection in treatment and research settings. Confidentiality would not provide sufficient protection, but privilege would. If granted privilege, peers can function more effectively, will be more likely to engage peers, and will not have to compromise the vital relationships that they build with clients and research subjects.

\section{References}

1. http://grants.nih.gov/grants/policy/coc/ background.htm

2. Davidson L, Chinman M, Sells D, \& Rowe M. (2006). Peer support among adults with serious mental illness: a report from the field. Schizophrenia Bulletin, 32(3), 443-50.

3. Boisvert RA, Martin LM, Grosek M, \& Clarie AJ. (2008). Effectiveness of a peer-support community in addiction recovery: participation as intervention. Occupational therapy international, 15(4), 205-220.

4. Sells D, Black R, Davidson L, \& Rowe M. (2008). Beyond generic support: incidence and impact of invalidation in peer services for clients with severe mental illness. Psychiatric Services, 59(11), 1322-1327.

5. Chinman M, Lucksted A, Gresen R, Davis M, Losonczy M, Sussner B, Martone L. (2008). Early experiences of employing consumer-providers in the VA. Psychiatric Services, 59(11), 1315-1321

6. Bernard v. Commonwealth, 424 Mass. 32; 673 N.E.2d 1220 (1996).

7. Cox v. Miller, NY 154 F. Supp. 2d 787 (2001).

8. Jaffee v. Redmond, 518 U.S. 1; 116 S. Ct. 1923 (1996).

9. Lecomte T, Wilde JB, Wallace CJ. (1999). Mental Health Consumers as Peer Interviewers. Psychiatric Services, 50(5), 693-5 